\title{
Activation of epidermal growth factor receptor gene is involved in transforming growth factor- $\beta$-mediated fibronectin expression in a chondrocyte progenitor cell line
}

\author{
HARUHIKO TAKEDA ${ }^{1,2}$, HIROFUMI INOUE ${ }^{2,5}$, TASTUHIKO KUTSUNA ${ }^{1,2}$, \\ NATSUKI MATSUSHITA ${ }^{2,3}$, TOSHIAKI TAKAHASHI ${ }^{1}$, SHOHEI WATANABE ${ }^{1}$, \\ SHIGEKI HIGASHIYAMA ${ }^{2,4,5}$ and HARUYASU YAMAMOTO ${ }^{1}$
}

\begin{abstract}
Departments of ${ }^{1}$ Bone and Joint Surgery, ${ }^{2}$ Biochemistry and Molecular Genetics, Ehime University Graduate School of Medicine; ${ }^{3}$ Gene Network Laboratory and ${ }^{4}$ Protein Network Laboratory, Center of Regenerative Medicine, Ehime University Graduate School of Medicine; ${ }^{5}$ Department of Cell Growth and Tumor Regulation, Proteo-Medicine Research Center, Ehime University, Shitsukawa, Toon, Ehime 791-0295, Japan
\end{abstract}

Received November 17, 2009; Accepted January 7, 2010

DOI: 10.3892/ijmm_00000381

\begin{abstract}
Chondrocytes produce many types of ECM to maintain elasticity and plasticity in articular cartilage of revolute joints. Both transforming growth factor $\beta$ (TGF- $\beta$ ) and bone morphogenetic proteins (BMPs) induce extracellular matrix proteins such as type II $\alpha 1$ collagen and aggrecan during chondrogenic differentiation in vitro. However, differences in the matrix gene expression pattern by the stimulation of TGF-ßs and BMPs remains unclear. In the present study, we created a customized PCR-based ECM array to investigate the pattern of ECM expression genes in the chondrocyte progenitor cell line ATDC5, that was stimulated by TGF-ßs or BMPs. Fibronectin $(F n)$ expression was drastically induced after TGF- $\beta$ stimulation, but not BMP-4. Epidermal growth factor receptor (Egfr) gene was also significantly activated in TGF- 31 -induced chondrogenic differentiation as compared to BMP-4-mediated differentiation. Furthermore, EGFRknockdown assay of the cells showed decreasing $F n$ expression during TGF-ß1-induced chondrogenic differentiation. These data indicated that Egfr gene activation by TGF- $\beta$ is involved in the differences in the expression of cellular matrix genes such as $F n$, as compared to the expression pattern induced by BMPs.
\end{abstract}

\section{Introduction}

Cartilage absorbs shock and provides a smooth articulating surface for proper joint mobility. Articular cartilage is

Correspondence to: Dr Hirofumi Inoue, Department of Biochemistry and Molecular Genetics, Ehime University Graduate School of Medicine, Shitsukawa, Toon, Ehime 791-0295, Japan

E-mail: hinoue66@m.ehime-u.ac.jp

Key words: transforming growth factor $ß 1$, epidermal growth factor receptor, fibronectin 1 , differentiation, chondrocyte comprised of chondrocytes and their surrounding hydrated proteoglycans such as aggrecan and collagen. Chondrocytes maintain cartilage homeostasis through a balance of the extracellular matrice (ECM) synthesis and the degradation, although they occupy $<5 \%$ of the total tissue volume (1).

Previous studies have shown that several growth factors are implicated in chondrogenesis, such as fibroblast growth factors (2,3), insulin-like growth factor (4-6), TGF- 3 (7-9), and bone morphogenetic proteins (BMP) $(3,10,11)$. The TGF- $\beta$ family, in particular, is strongly associated with chondrogenic differentiation.

TGF-ßs signal through heteromeric TGF- 3 s receptors composed of type I and type II serine/threonine kinases. The receptor associated Smads, Smad2 and 3, was phosphorylated by activated type I receptors after heteromeric receptor complex formation. The phosphorylated Smads associates with Smad4, translocate to the nucleus, and act as transcription factors. In contrast, BMPs transduce the signal via type I and type II BMP receptors complex. Then, Smad1, 5 , and 8, the BMPs signal-associated Smads, are phosphorylated by the activated type I BMP receptor, and regulate gene expression with Smad4 (12). The TGF-ßs also appear to signal through the MAPK pathway via the MAPKKK, TAK1 (TGF- $\beta$ activated kinase), and its associated partner TAB 1 (TAK1 binding protein) $(13,14)$.

TGF- $\beta$ is a multifunctional cytokine that is crucially involved in multiple processes throughout development, ECM synthesis, cell proliferation, differentiation, and tissue repair. Baker et al reported that, in cartilage, TGF- $\beta 1$ promotes cartilage matrix synthesis and induces the activity of tissue inhibitor of metalloproteinase-3 (TIMP-3), which inhibits matrix metalloproteinases, aggrecanases, and TNF- $\beta$ converting enzyme, all of which are implicated in articular cartilage degradation and joint inflammation (15). In contrast, BMPs and their receptors are required for chondrogenesis and are expressed throughout the growth plate and perichondrium $(16,17)$. BMPs, but not TGF- 3 promote differentiation at a late stage, which are required for the induction of type $\mathrm{X}$ 
collagen, and leads to ossification $(18,19)$. Though TGF-ßs and BMPs have different characteristics, they both induce major cartilage matrix synthesis such as aggrecan and type II $\alpha 1$ collagen through different pathways, and they are both important for chondrogenic regulation.

In the present study, we demonstrated that TGF- $\beta$, but not BMP-4, induces Fibronectin ( $F n$ ) expression during the chondrogenic differentiation of ATDC5 cells. Furthermore, expression of the EGFR ligands, Tgf- $\alpha$ and $H b-e g f$, and Egf receptor $(E g f r / E r b B 1)$ significantly increased during the TGF- $\beta$-induced chondrogenic differentiation. The induction of $F n$ gene by TGF- $\beta$ stimulation was disturbed during chondrogenic differentiation in the EGFR-knocked-down ATDC5 cells. These data indicated that the EGFR signaling cascade is associated with FN synthesis during TGF- 3 -induced chondrogenic differentiation.

\section{Materials and methods}

Cell cultures. ATDC5 (RIKEN cell bank; Tsukuba, Japan) was purchased from the RIKEN cell bank. ATDC5 cells were maintained in a 1:1 mixture of DME and Ham's F-12 (DME/F12) medium (Wako, Osaka, Japan) containing 5\% FBS (Nichirei Bioscience, Tokyo, Japan) and TS, which consisted of $10 \mu \mathrm{g} / \mathrm{ml}$ human transferrin (T; Roche Diagnostics, Mannheim, Germany), and $3 \times 10^{-8} \mathrm{M}$ sodium selenite (S; Sigma, St. Louis, MO, USA), as previously described $(11,20,21)$. The medium was replaced every other day. In some experiments, ATDC5 cells were plated at a density of $6 \times 10^{4}$ cells per $35-\mathrm{mm}$ dish and cultured in DME/F12 medium containing 5\% FBS and TS. On day 3 after the cells were plated, the culture medium was replaced by DME/F12 medium containing 5\% FBS, TS, and either $10 \mu \mathrm{g} / \mathrm{ml}$ human insulin (I; Roche Diagnostics) or human recombinant BMP-4 (R\&D Systems, Minneapolis, MN, USA) or human recombinant TGF- $B 1$ (R\&D Systems). The medium and the ligands were replaced every other day.

Western blotting. The experiments were terminated by aspirating the culture medium and washing the cells three times with ice-cold PBS. Cell lysates were prepared in $0.5 \mathrm{M}$ Tris lysis buffer ( $\mathrm{pH}$ 6.8) containing $2 \%$ sodium dodecyl sulfate, 2-mercaptoethanol, and 5\% glycerol and then subjected to sonication. They were stored at $-80^{\circ} \mathrm{C}$ until use. For Western blot analysis, equal amounts of proteins were pooled from triplicate samples and separated by $6 \%$ sodium dodecyl sulfate-polyacrylamide gel electrophoresis (SDS-PAGE). Following SDS-PAGE, proteins were transferred to nitrocellulose membranes. Immunoblots were blocked with $5 \%$ milk in Tris-buffered saline with $0.1 \%$ Tween-20 and then probed overnight with primary antibodies (1:1000 dilution). Western blotting was performed by using rabbit monoclonal antibodies against EGFR (Cell Signaling Technology, Danvers, MA, USA) and mouse monoclonal antibodies against $\beta$-actin (Sigma), followed by incubation with anti-rabbit $\mathrm{IgG}$ or antimouse IgG. The results were visualized by using the ECL Plus detection kit (Pharmacia) and quantified with Gel-Pro Analyzer software (Media Cybernetics, Silver Spring, MD, USA). Where indicated, the blots were stripped according to the ECL Plus protocol prior to re-probing.
Table I. Primer used for qRT-PCR.

\begin{tabular}{cl}
\hline Gene & \multicolumn{1}{c}{ Primer } \\
\hline Collagen IIa1 & \\
Forward & 5'-CAGGATGCCCGAAAATTAGGG-3' \\
Reverse & 5'-ACCACGATCACCTCTGGGT-3' \\
Aggrecan & \\
Forward & 5'-CCTGCTACTTCATCGACCCC-3' \\
Reverse & 5'-AGATGCTGTTGACTCGAACCT-3' \\
ErbB1 & \\
Forward & 5'-GCCATCTGGGCCAAAGATACC-3' \\
Reverse & 5'-GTCTTCGCATGAATAGGCCAAT-3' \\
ErbB2 & \\
Forward & 5'-CCAAGGCACAAGTAACAGGCT-3' \\
Reverse & 5'-CCACGGTGTTGAGGGCAAT-3' \\
ErbB3 & \\
Forward & 5'-AAGTGACAGGCTATGTACTGGT-3' \\
Reverse & 5'-GCTGGAGTTGGTATTGTAGTTCA-3' \\
Tgfa & \\
Forward & 5'-CACTCTGGGTACGTGGGTG-3' \\
Reverse & 5'-CACAGGTGATAATGAGGACAGC-3' \\
Hb-egf & \\
Forward & 5'-TGCCGTCGGTGATGCTGAACT-3' \\
Reverse & 5'-GGTTCAGATCTGTCCCTTCCAAGTC-3' \\
Fibronectin & \\
Forward & 5'-TTCAAGTGTGATCCCCATGAAG-3' \\
Reverse & 5'-CAGGTCTACGGCAGTTGTCA-3' \\
Reverse & 5'-GGGGCTGTACTGCTTAACCAG-3' \\
\hline & \\
\hline
\end{tabular}

Quantitative reverse-transcription polymerase chain reaction $(q R T-P C R)$. Total RNA was extracted from cells by using TRIzol reagent (Invitrogen, La Jolla, CA, USA), and firststrand cDNA was synthesized from $1 \mu \mathrm{g}$ of RNA by using Superscript III (Invitrogen). The Applied Biosystems 7300 real-time PCR system (Applied Biosystems, Foster City, CA, USA) was used to perform quantitative real-time RT-PCR was performed in a $25-\mu 1$ reaction volume containing $15 \mu 1$ of the SYBR Green qPCR Supermix Universal (Invitrogen), $1 \mu \mathrm{l}$ of the RT reaction mixture, and $200 \mathrm{nM}$ primers. The primer sequences are listed in Table I. All primers generated PCR fragments with the correct sizes, and non-specific products were not generated; thus, the specificity of the realtime RT-PCR was confirmed (data not shown). The cycle threshold $(\mathrm{Ct})$ value for each gene of interest was measured for each RT sample.

Lentiviral shRNA-mediated knockdown of EGFR in ATDC5 cells. To produce ATDC5 cells in which the expression of the Egfr gene is suppressed during long-term culture, a lentivirusmediated RNA interference-knockdown system was applied 
to the ATDC5 cells. An HIV-based self-inactivating lentiviral expression vector (CSII-CMV-MCS-IRES-Bsd) and two packaging vectors (pCAG-HIVgp and pCMV-VSV-G-RSVRev) were obtained from Dr Hiroyuki Miyoshi (RIKEN BioResource Center, Japan) (22). A human H1-RNA pol III promoter $(-217$ to +1$)$ DNA fragment was amplified by polymerase chain reaction. To drive the expression of a small hairpin RNA shRNA, the H1 promoter was into the U3 region of the 3'-long terminal repeat (LTR) in the original lentiviral vector, as described previously (23), in order to drive the expression of a small hairpin RNA (shRNA). In the modified shRNA expression vector, termed CSII-CMVIRES-Bsd-H1, BamHI and EcoRI sites were introduced into the $3^{\prime}$ end of the $\mathrm{H} 1$ promoter, allowing the insertion of the shRNA template. The original algorithm (B-Algo ${ }^{\mathrm{TM}}$ ) from B-Bridge International (Tokyo, Japan) was used to design specific shRNA target sequences. The target sequence of the mouse Egfr gene for knockdown was 5'-GGGAAATGCT CTTTATGAA-3', corresponding to the 324-342 nucleotide positions of the mouse Egfr coding sequence (GenBank accession no. NM_207655). The targeting sequence for EGFP-shRNA, (5'-CTACAACAGCCACAACGTC-3') was selected as a negative control. To construct the shRNA expression cassette, two complementary oligonucleotides were synthesized, annealed, and inserted between the Bam HI and EcoRI sites just downstream of the H1 promoter. The shRNA cassette features a TTCAAGAGA loop situated between the sense and reverse complementary targeting sequences and a TTTTT terminator at the 3'-end as described previously (24). The lentiviral vector also carries a blasticidinresistant gene as a transduction selection marker. Lentiviral particles were generated by using a standard transfection procedure. After transduction of the transgenes, a pool of blastidin-resistant ATDC5 was used to analyze the gene expression downstream of the EGFR-dependent signal during chondrogenic differentiation.

$R T^{2}$ Profiler Customized PCR array system. The expression levels of 42 chondrogenic-related mouse genes were examined by using the customized $\mathrm{RT}^{2}$ Profiler PCR array (SuperArray Bioscience, Frederick, MD, USA). The TRIzol reagent (Invitrogen) and Superscript III (Invitrogen) were used to isolate total RNA from the wild-type ATDC5 cells and ATDC5 cells that were infected with shRNA lentivirus vector against Gfp (shGfp/ATDC5) or Egfr (shEgfr/ATDC5). cDNA was synthesized from $1 \mu \mathrm{g}$ of RNA by using a SuperScript RT II enzyme (Invitrogen). The Applied Biosystems 7300 real-time PCR system and $\mathrm{RT}^{2}$ Profiler PCR array system were used to perform PCR, according to the manufacturer's instructions. The mRNA expression level of each gene in shEgfr/ATDC5 was normalized against the housekeeping gene expression (Gusb, Hprt1, Hspcb, Gapdh, and Actb), and then compared with the data obtained from shGfp/ATDC5. Individual RNA samples from the cells in each group were subjected to quantitative RT-PCR to confirm the results. The primers used for the $\mathrm{RT}^{2}$ Profiler Customized PCR array are listed in Table II.

Statistical analysis. The results are presented as mean \pm SE. The two groups were compared by using the Student's t-test.
Table II. Primers used for $\mathrm{RT}^{2}$ profiler customized PCR array system.

\begin{tabular}{|c|c|}
\hline CollagenIal & Collal \\
\hline CollagenIIal & Col2al \\
\hline CollagenIIIal & Col3al \\
\hline CollagenIVa2 & Col4a2 \\
\hline CollagenVal & Col5al \\
\hline CollagenVIIal & Col7a1 \\
\hline CollagenIX 1 & Col9al \\
\hline CollagenXa1 & Colloal \\
\hline CollagenXIal & Coll1 $\alpha 1$ \\
\hline CollagenXII 1 & Coll2al \\
\hline CollagenXVIIa 1 & Col17al \\
\hline CollagenXVIIIa 1 & Coll8al \\
\hline Aggrecan & Acan \\
\hline Biglycan & $B g n$ \\
\hline Brevican & Bcan \\
\hline Chondroadherin & Chad \\
\hline Colin & Corin \\
\hline Decolin & Dcn \\
\hline Fibronectin & $F n$ \\
\hline Filamin $\alpha$ & $F \ln \alpha$ \\
\hline Filamin $\beta$ & $F \ln \beta$ \\
\hline Filamin $C, \gamma$ & $F \ln c$ \\
\hline Glypican1 & $G p c l$ \\
\hline Glypican2 & $G p c 2$ \\
\hline Glypican3 & $G p c 3$ \\
\hline Glypican3 & $G p c 3$ \\
\hline Glypican4 & Gpc4 \\
\hline Glypican5 & $G p c 5$ \\
\hline Glypican6 & Gpc6 \\
\hline Gelsolin & Gsn \\
\hline Necdin & $N d n$ \\
\hline Osteoglycan & Ogn \\
\hline Syndecanl & $S d c 1$ \\
\hline Syndecan2 & $S d c 2$ \\
\hline Syndecan3 & $S d c 3$ \\
\hline Syndecan4 & $S d c 4$ \\
\hline Chondroitin sulfate synthase 1 & Chsyl \\
\hline Chondroitin sulfate synthase 3 & Chsy3 \\
\hline Hyaluronan synthase1 & Hasl \\
\hline Hyaluronan synthase 2 & Has2 \\
\hline Hyaluronan synthase 3 & Has3 \\
\hline Versican & Vcanl \\
\hline Elastin & $E \ln$ \\
\hline
\end{tabular}

Analysis of variance with Bonferroni's post-hoc test was used for multiple comparisons. Statistical significance was established at $\mathrm{p}<0.05$.

\section{Results}

Chondrocyte-related ECM gene expression after treatment with TGF- $\beta 1$ and BMP-4. We analyzed the gene expression 

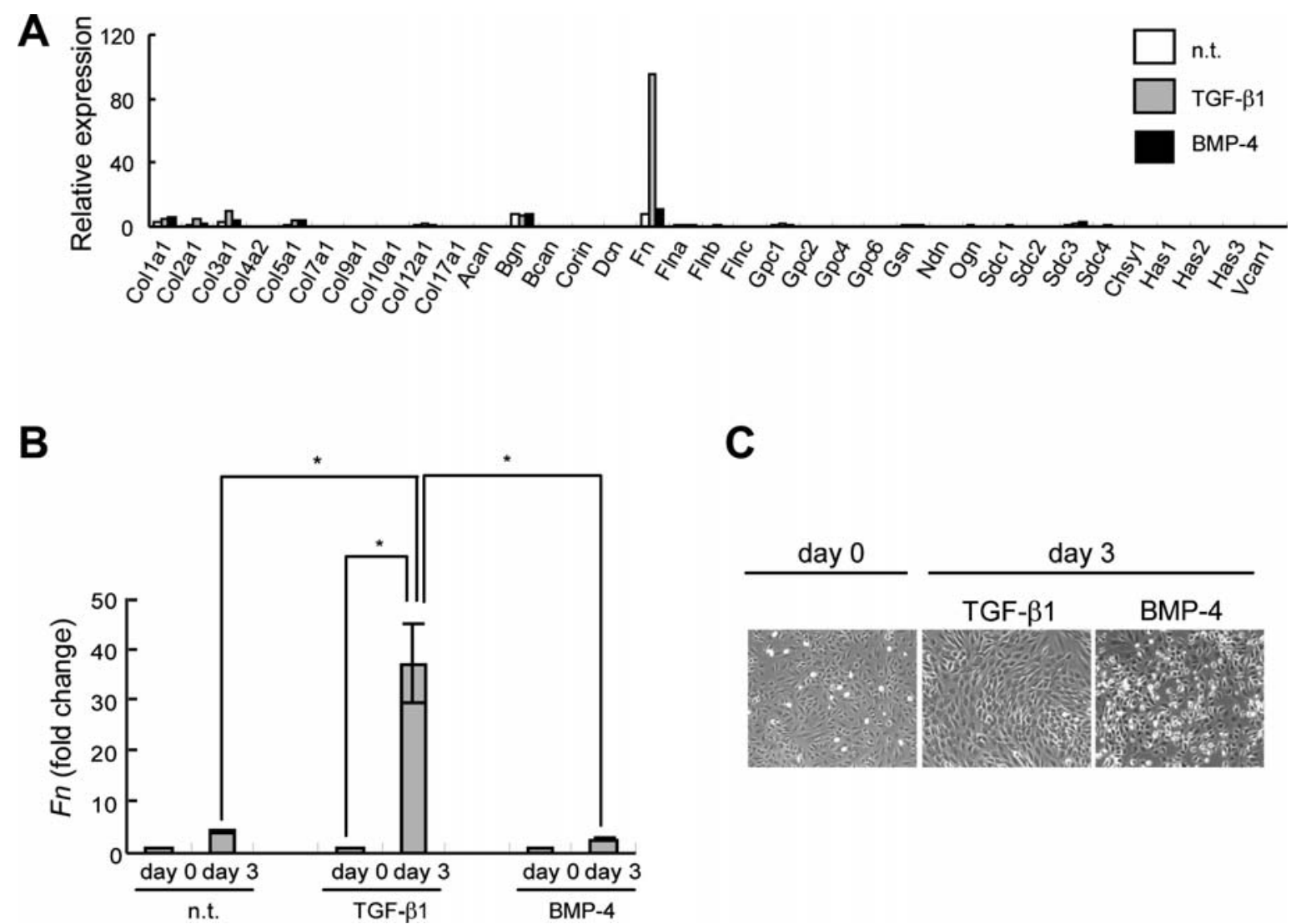

Figure 1. Comparison between chondrocyte-related genes by treatment with TGF- 11 and BMP-4. The expression of chondrocyte-related genes in ATDC5 cells were assessed by qRT-PCR in ATDC5 cells. (A) Expression levels of chondrocyte-related ECM genes after treatment with TGF- 11 or BMP-4 for 3 days. Expression values shown are relative to the average value of housekeeping genes (Gusb, Hprt1, Hspcb, Gapdh, and Actb). (B) The expression of Fibronectin during chondrogenic differentiation induced by TGF- 31 or BMP-4 for 3 days. The results are normalized to Hprt1 and presented as a fold change relative to the expression of day 0. (C) Morphological findings of ATDC5 cells by treatment with TGF-B1 or BMP-4 for 3 days. n.t., no treatment.

profiles of chondrocyte-related ECM genes during chondrogenic differentiation of ATDC5 cells treated with TGF- 11 or BMP-4. We performed qRT-PCR to analyze the mRNA expression levels of the chondrogenic-related genes, and we assessed the expression of chondrocyte-related ECM genes by using an $\mathrm{RT}^{2}$ Profiler PCR array system customized for profiling ECM genes. We compared the expression levels of genes in 3-day-differentiated cells treated with TGF-B1 or BMP-4. Fibronectin $(F n)$ was greatly up-regulated in TGFB1-treated cells, as compared to untreated cells or BMP-4treated cells (Fig. 1A). The significantly higher expression levels of $F n$ in TGF-ß1-treated cells was confirmed by qRTPCR with another specific primer set for the $F n$ gene (Fig. 1B). TGF- $\beta 1$-treated ATDC5 cells adopted, a spindle-shaped phenotype, while BMP-4-treated cells displayed a round phenotype on day 3 after differentiation (Fig. 1C).

TGF- $\beta 1$, but not BMP-4, strongly up-regulates the gene expression of EGFR in ATDC5 cells. In mesangial cells from the kidney, TGF- $\beta$ treatment stimulates the processing and release of HB-EGF which in turn transactivates the EGFRmediated ERK and p38 MAPK cascades that regulate $F n$ gene transcription (25). Therefore, we examined whether or not the expression of the $E r b B$ gene family, including $E g f r$, is dependent on TGF- $\$ 1$ or BMP-4 signal during chondrogenic differentiation. We performed qRT-PCR to analyze the
mRNA expression levels of Egfr, and $E r b B 2, E r b B 3$ and ErbB4 in ATDC5 cells treated with TGF- 31 or BMP-4. TGF- $\beta$, but not BMP-4, strongly up-regulated the gene expression of Egfr (Fig. 2A). The up-regulation of ErbB2 and $B 3$ was significantly less than the up-regulation of $E g f r$ in TGF-B1-treated cells. ErbB4 was not detected after stimulation by either ligand (data not shown).

To determine if the activation of the Egfr gene is dependent on the concentration of TGF-ß1, ATDC5 cells were stimulated with four different concentrations of TGF- $\beta 1(0,0.1,1$, and $10 \mathrm{ng} / \mathrm{ml}$ ) for 3 days. We found that $E g f r$, along with the major chondrocyte-specific ECM genes such as CollagenIIal (ColIIal) and aggrecan (Acan), was up-regulated in a TGF$\beta 1$ dose-dependent manner (Fig. 2B). Western blot analysis showed that the EGFR protein level was also induced by TGF-ß1 (Fig. 2C). We also analyzed the expression of EGFR ligands, $T G F-\alpha$ and $H b$-egf, after treatment with TGF- $\beta 1$ and BMP-4 during chondrogenic differentiation. $T G F-\alpha$ and $H b-e g f$ were more strongly expressed during induction with TGF- 31 than with BMP-4 (Fig. 2D). Thus, these findings indicate that TGF- $\beta 1$-induced chondrogenic cells could activate their own EGFR signaling cascade by the autocrine secretion of TGF- $\alpha$ and HB-EGF.

A knockdown assay by shRNA against Egfr. To investigate whether EGFR affects chondrogenic differentiation with 
A
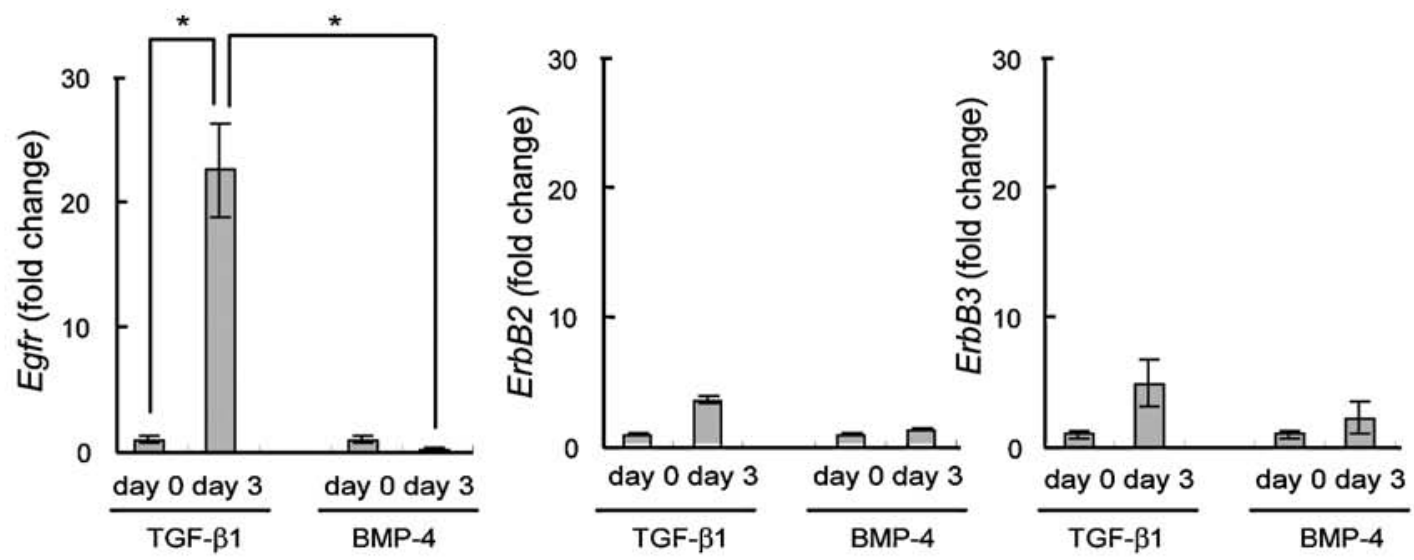

B
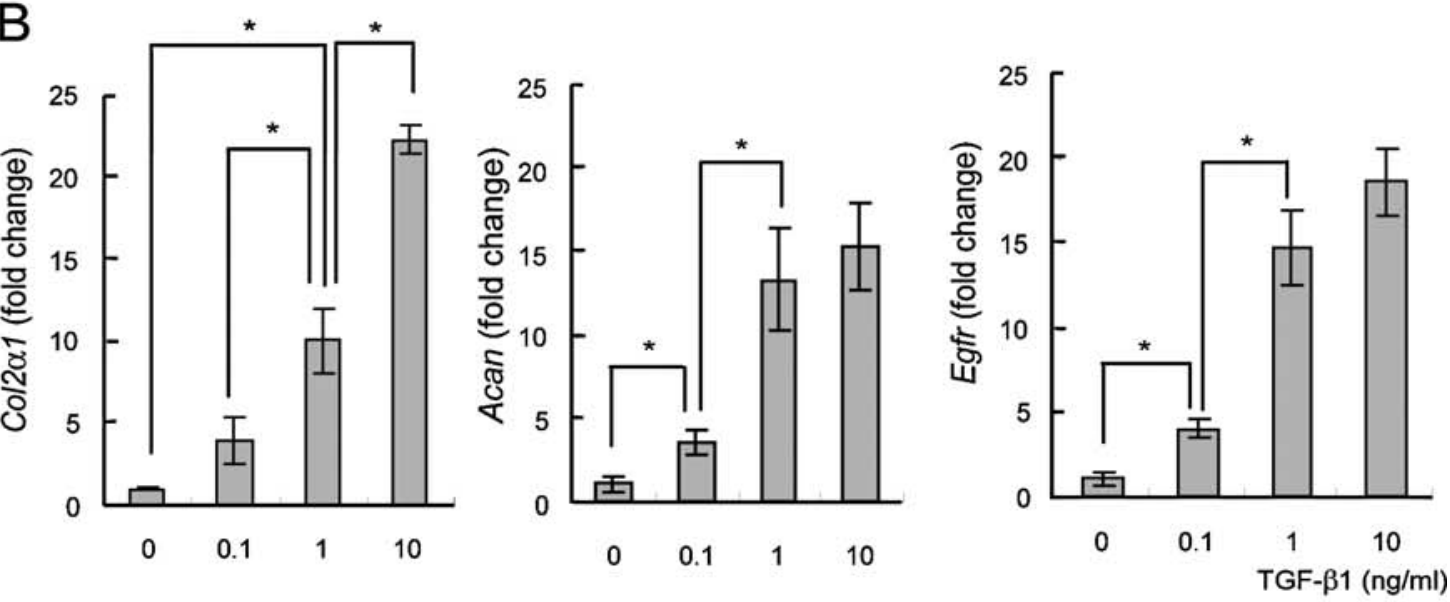

C
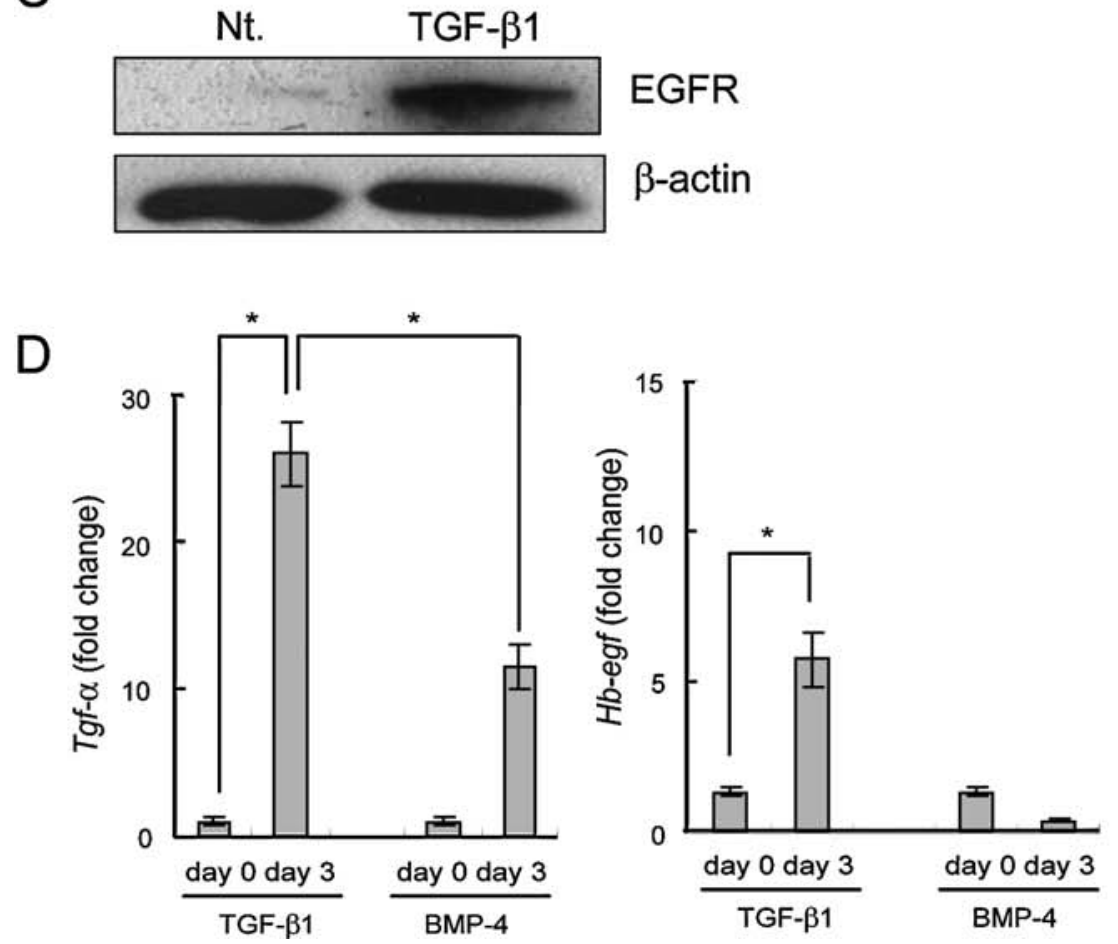

Figure 2. Egfr was induced during chondrogenic differentiation by treatment with TGF-ß1 but not BMP-4. (A) ATDC5 differentiated into chondrocytes by TGF-B1 $(10 \mathrm{ng} / \mathrm{ml})$ or BMP-4 $(200 \mathrm{ng} / \mathrm{ml})$ treatment in ATDC5 cells. The gene expression levels of Egfr and ErbB2, 3, and 4 were detected by quantitative real-time RT-PCR (qRT-PCR). Erbb4 was not detected by qRT-PCR. The results are normalized to Hprt1 and presented as a fold change relative to the expression of day 0. (B) To examine dose effects, four concentrations of TGF- $\$ 1(0,0.1,1$, and $10 \mathrm{ng} / \mathrm{ml})$ were added to ATDC5 cells. The mRNA expression levels of CollagenIIal (ColIIa1), Aggrecan (Acan), and Egfr were detected by qRT-PCR. (C) Western blots of ATDC5 cells were probed for EGFR. Antibodies against $B$-actin were used as a loading control. (D) The gene expression levels of EGF ligands (Tgf- $\alpha$ and $H b$-egf) during chondrogenic differentiation by the treatment with TGF- 11 or with BMP-4 were detected by qRT-PCR. n.t., no treatment. 
A

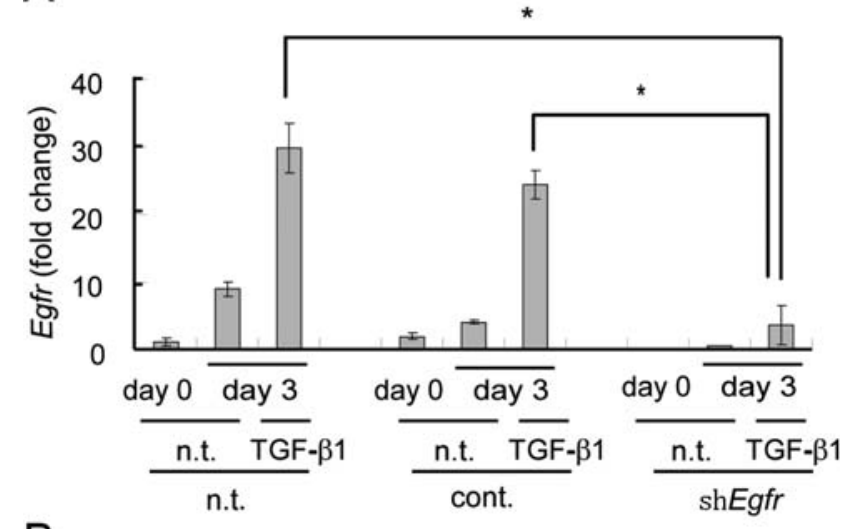

B
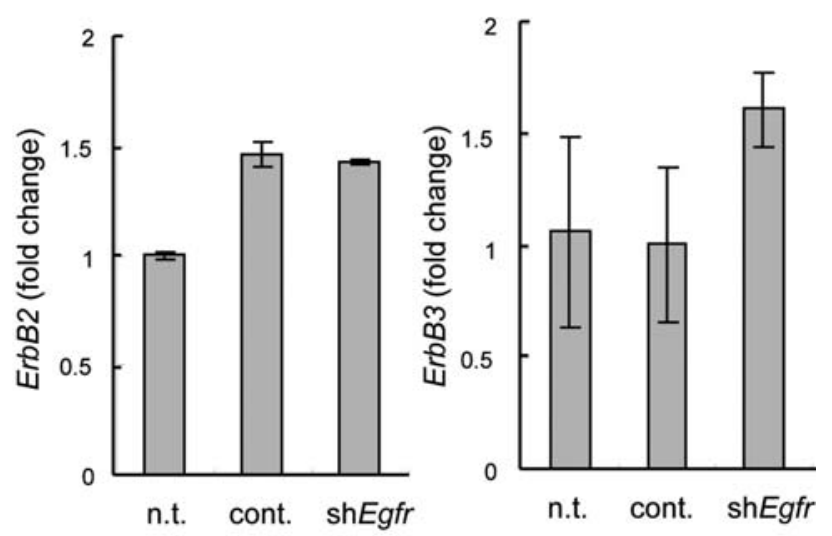

C

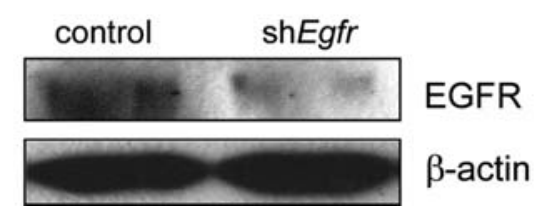

Figure 3. A knockdown assay by shRNA against Egfr. A knockdown assay of Egfr mRNA is performed to see the function of EGFR during chondrogenesis. (A) Gene expression of Egfr was compared between shEgfr/ ATDC5 and shGfp/ATDC5 using qRT-PCR. The results are normalized to Hprtl and presented as a fold change relative to the expression of day 0 . The expression of Egfr in a comparison between $\operatorname{sh} E g f r / A T D C 5$ and $\operatorname{sh} G f p /$ ATDC5 on day 3 of TGF-ß1-induced differentiation. (B) Gene expression levels of Erbb2 and 3 were compared between shEgfr/ATDC5 and shGfp/ ATDC5. (C) Western blots of ATDC5 were probed for EGFR. Antibodies against $B$-actin were used as a loading control. n.t., no treatment.

TGF- 31 treatment, we performed an Egfr knockdown assay with lentivirus vectors carrying two shRNAs targeting Egfr (lenti-shEgfr) or green fluorescent protein (lenti-shGfpy), which was used as a control. We infected ATDC5 cells with each of lenti-shRNA and assessed the Egfr suppression by RT-PCR and Western blotting. Egfr gene expression in ATDC5 cells was more effectively down-regulated by infection with lenti-shEgfr than by infection with lenti-shGfp (Fig. 3A). In contrast, the gene expression levels of ErbB2 and ErbB3 were not down-regulated in shEgfr/ATDC5 (Fig. 3B). Western blotting revealed that the protein level of EGFR was significantly decreased in shEgfr/ATDC5 (Fig. 3C).

EGFR knockdown leads to the down-regulation of Fn during chondrogenic differentiation induced by TGF- $\beta 1$ treatment.
We used the $\mathrm{RT}^{2}$ Profiler Customized PCR array system to examine the effect of EGFR knockdown on the expression of ECM and matrix metalloprotease genes in TGF-131-treated parental ATDC5 cells, shEgfr/ATDC5 or shGfp/ATDC5. shEgfr/ATDC5 had a lower expression of four ECM genes, CollagenXa1 (ColXa1), CollagenXVIIal (ColXVIIa1), Acan, and $F n$, in ECM genes as compared to parental ATDC5 cells and shGfp/ATDC5 (Fig. 4A). The expression level of $F n$ was significantly lower in shEgfr/ATDC5 than in shGfp/ATDC5 in a time-dependent manner with TGF- 31 treatment (Fig. 4B). These data suggest that the TGF- $\beta$ signaling could regulate certain ECM genes, such as FN via EGFR signaling during chondrogenesis.

\section{Discussion}

In our study, we focused on the differences in the pattern of ECM genes induced by TGF- $\beta 1$ and BMP-4. The customized RT-PCR array analysis showed that there was a definite difference in $F n$ gene expression. FN is a large dimeric glycoprotein that functions primarily as a connecting molecule in the ECM by both cell-matrix and matrix-matrix interactions. FN is involved in cell adhesion, migration, and ECM accumulation in processes such as embryogenesis, wound healing, blood coagulation, host defense, and metastasis. Various isoforms are produced from a single FN gene, and full length recombinant FN reduces spreading and promotes the condensation and chondrogenesis of limb mesenchymal cells (26). FN expression is increased in areas of cellular condensation that are decreased as cytodifferentiation proceeds $(27,28)$. According to recent studies, isoform switching of $F n$ mRNA is important for chondrogenic differentiation (29-31) and that TGF-ß1 treatment during chondrogenic differentiation of ATDC5 cells increases the expression of $\mathrm{FN}$ isoforms that lack the extra domain A and B during chondrogenic differentiation of ATDC5 cells $(32,33)$. Regulation of both quantity and quality of FN by TGF- $\beta 1$ could be involved in the early stage of chondrogenesis.

It was previously reported that HB-EGF and EGFR transactivation are involved in TGF- $\beta$-mediated FN expression in mesangial cells, however, the new protein synthesis induced by TGF- $\beta$ did not participate in induction of FN expression (25). In contrast, our study found that EGFR expression in ATDC5 cells is induced by TGF- $\beta$ treatment and that this expression is crucial for $F n$ gene expression. We believe that differences in the cell types are responsible for the different results of these two studies. The study that $F n$ mRNA is stabilized by TGF- $\beta$-dependent protein synthesis in cardiac fibroblasts supports this speculation (34).

Our study also showed that the knockdown of EGFR expression in the chondrogenic ATDC5 cells reduces the expression levels of several ECM genes such as ColX $\alpha 1$, ColXVIIa 1, and Acan as well as Fn (Fig. 4A). It has been even reported that expression of TGF- $\alpha$, a member of the EGFR ligand family, in mouse lungs caused extensive pulmonary fibrosis without inflammation (35). A recent study indicated that EGF receptor tyrosine kinase inhibitors diminish TGF- $\beta$-induced pulmonary fibrosis (36). Amphiregulin, another member of the EGFR ligand family, is involved in 


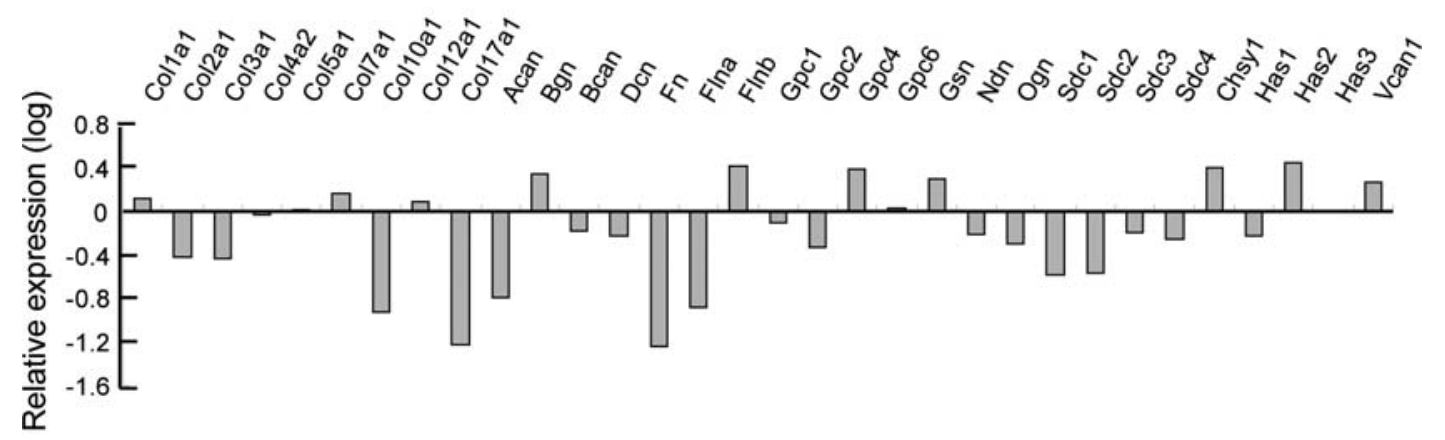

B

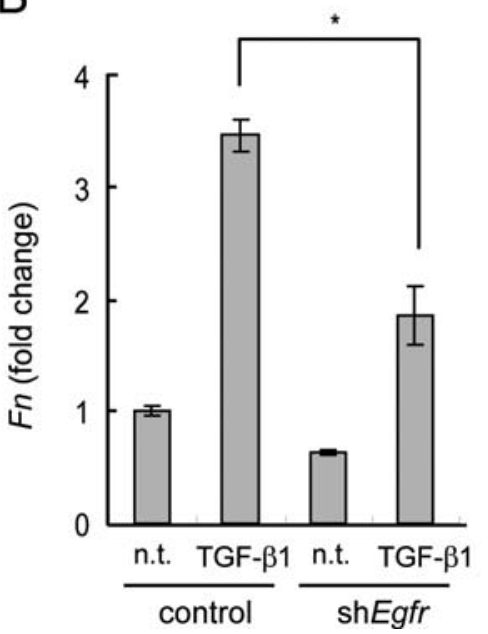

Figure 4. EGFR knockdown leads to downregulation of Fibronectin 1 during chondrogenic differentiation by treatment with TGF-B1. (A) The expression of ECM genes associated with chondrocytes in a comparison between $\operatorname{sh} E g f r / A T D C 5$ and shGfp/ATDC5 on day 3 of TGF-B1-induced differentiation. Expression values shown are relative to the average value of housekeeping genes (Gusb, Hprt1, Hspcb, Gapdh, and Actb). (B) The expression of Fibronectin 1 during TGF- $\beta 1$-induced differentiation of $\operatorname{sh}$ Egfr/ATDC5 and shGfp/ATDC5. The results are normalized to Hprt1 and presented as a fold change relative to the expression of day 0 . n.t., no treatment.

the development of mouse liver fibrosis (37). Other studies showed that TGF- $\alpha$, HB-EGF, or EGFR plays a critical part in pancreatic fibrosis formation $(38-40)$. These findings suggest that EGFR signaling is important in extracellular matrix production as with cell growth and survival.

In conclusion, the expression of EGFR and its ligands is required for the TGF- $\beta$-mediated expression of ECM genes such as $F n$ during the chondrogenic differentiation of ATDC5 cells. BMP-4, which induces late-stage chondrocyte differentiation, did not induce the Egfr gene products that regulate ECM genes. We concluded that EGFR signaling in chondrocytes might prevent mineralization and subsequent ossification such that chondrocytes continue to produce articular cartilage-specific ECM.

\section{Acknowledgements}

The study was supported by Grant-in-Aid for Scientific Research to H. Takeda from Ehime University. We thank Drs S. Fukuda, H. Ohnuki, H. Nakayama, D. Miwa, and M. Kurokawa for valuable discussions. We also thank Mrs. S. Matshushita for help with technical support.

\section{References}

1. Kuettner KE, Aydelotte MB and Thonar EJ: Articular cartilage matrix and structure: a minireview. J Rheumatol 27: S46-S48, 1991.
2. Karsenty G: Genetics of skeletogenesis. Dev Genet 22: 301-313, 1998.

3. Niswander L and Martin GR: FGF-4 and BMP-2 have opposite effects on limb growth. Nature 361: 68-71, 1993.

4. Takigawa M, Okawa T, Pan H, et al: Insulin-like growth factors I and II are autocrine factors in stimulating proteoglycan synthesis, a marker of differentiated chondrocytes, acting through their respective receptors on a clonal human chondrosarcomaderived chondrocyte cell line, HCS-2/8. Endocrinology 138: 4390-4400, 1997.

5. Avruch J: Insulin signal transduction through protein kinase cascades. Mol Cell Biochem 182: 31-48, 1998.

6. White MF and Yenush L: The IRS-signaling system: a network of docking proteins that mediate insulin and cytokine action. Curr Top Microbiol Immunol 228: 179-208, 1998.

7. Denker AE, Nicoll SB and Tuan RS: Formation of cartilagelike spheroids by micromass cultures of murine C $3 \mathrm{H} 10 \mathrm{~T} 1 / 2$ cells upon treatment with transforming growth factor-beta 1 . Differentiation 59: 25-34, 1995.

8. Chimal-Monroy J and Díaz de León L: Differential effects of transforming growth factors beta 1 , beta 2 , beta 3 and beta 5 on chondrogenesis in mouse limb bud mesenchymal cells. Int $\mathbf{J}$ Dev Biol 41: 91-102, 1997.

9. Johnstone B, Hering TM, Caplan AI, Goldberg VM and Yoo JU: In vitro chondrogenesis of bone marrow-derived mesenchymal progenitor cells. Exp Cell Res 238: 265-272, 1998.

10. Denker AE, Haas AR, Nicoll SB and Tuan RS: Chondrogenic differentiation of murine C3H10T1/2 multipotential mesenchymal cells: I. Stimulation by bone morphogenetic protein-2 in highdensity micromass cultures. Differentiation 64: 67-76, 1999.

11. Shukunami C, Ohta Y, Sakuda M and Hiraki Y: Sequential progression of the differentiation program by bone morphogenetic protein-2 in chondrogenic cell line ATDC5. Exp Cell Res 241: $1-11,1998$.

12. Kawabata M, Imamura T, Inoue $\mathrm{H}$, et al: Intracellular signaling of the TGF- $\beta$ superfamily by Smad proteins. Ann NY Acad Sci 886: 73-82, 1999. 
13. Yamaguchi K, Shirakabe K, Shibuya H, et al: Identification of a member of the MAPKKK family as a potential mediator of TGF-ß signal transduction. Science 270: 2008-2011, 1995.

14. Shibuya $\mathrm{H}$, Yamaguchi $\mathrm{K}$, Shirakabe $\mathrm{K}$, et al: TAB1: an activator of the TAK1 MAPKKK in TGF-ß signal transduction. Science 272: 1179-1182, 1996

15. Baker AH, Edwards DR and Murphy G: Metalloproteinase inhibitors: biological actions and therapeutic opportunities. J Cell Sci 115: 3719-3727, 2002.

16. Retting KN, Song B, Yoon BS and Lyons KM: BMP canonica Smad signaling through Smad1 and Smad5 is required for endochondral bone formation. Development 136: 1093-1104, 2009.

17. Yoon BS and Lyons KM: Multiple functions of BMPs in chondrogenesis. J Cell Biochem 93: 93-103, 2004.

18. Minina E, Schneider S, Rosowski M, Lauster R and Vortkamp A: Expression of Fgf and TGF- $\beta$ signaling related genes during embryonic endochondral ossification. Gene Expr Patterns 6: 102-109, 2005.

19. Fujii M, Takeda K, Imamura T, et al: Roles of bone morphogenetic protein type I receptors and Smad proteins in osteoblast and chondroblast differentiation. Mol Biol Cell 10: 3801-3813, 1999.

20. Shukunami C, Akiyama H, Nakamura T and Hiraki Y: Requirement of autocrine signaling by bone morphogenetic protein-4 for chondrogenic differentiation of ATDC5 cells. FEBS Lett 469: 83-87, 2000.

21. Watanabe H, de Caestecker MP and Yamada Y: Transcriptional cross-talk between Smad, ERK1/2, and p38 mitogen-activated protein kinase pathways regulates transforming growth factor- $\beta$ induced aggrecan gene expression in chondrogenic ATDC5 cells. J Biol Chem 276: 14466-14473, 2001

22. Miyoshi H, Blomer U, Takahashi M, Gage FH and Verma IM: Development of a self-inactivating lentivirus vector. J Virol 72: 8150-8157, 1998.

23. Wiznerowicz M and Tronto D: Conditional suppression of cellular genes: Lenivirus vector-mediated drug-inducible RNA interference. J Virol 77: 8957-8961, 2003.

24. Qin XF, An DS, Chen IS and Baltimore D: Inhibiting HIV-1 infection in human $\mathrm{T}$ cells by lentiviral-mediated delivery of small interfering RNA against CCR5. Proc Natl Acad Sci 100: 183-188, 2003

25. Uchiyama-Tanaka $\mathrm{Y}$, Matsubara $\mathrm{H}$, et al: Involvement of HBEGF and EGF receptor transactivation in TGF- $\beta$-mediated fibronectin expression in mesangial cells. Kidney Int 62: 799-808, 2002.

26. White DG, Hershey HP, Moss JJ, Daniels H, Tuan RS and Bennett VD: Functional analysis of fibronectin isoforms in chondrogenesis: Full-length recombinant mesenchymal fibronectin reduces spreading and promotes condensation and chondrogenesis of limb mesenchymal cells. Differentiation 71: 251-261, 2003 .

27. Dessau W, von der Mark H, von der Mark K and Fischer S Changes in the patterns of collagens and fibronectin during limb-bud chondrogenesis. Changes in the patterns of collagens and fibronectin during limb-bud chondrogenesis. J Embryol Exp Morphol 57: 51-60, 1980.
28. Kulyk WM, Upholt WB and Kosher RA: Fibronectin gene expression during limb cartilage differentiation. Development 106: 449-455, 1989.

29. Gehris AL, Oberlender SA, Shepley KJ, Tuan RS and Bennett VD: Fibronectin mRNA alternative splicing is temporally and spatially regulated during chondrogenesis in vivo and in vitro. Dev Dyn 206: 219-230, 1996.

30. Gehris AL, Stringa E, Spina J, Desmond ME, Tuan RS and Bennett VD: The region encoded by the alternatively spliced exon IIIA in mesenchymal fibronectin appears essential for chondrogenesis at the level of cellular condensation. Dev Biol 190: 191-205, 1997.

31. Bennett VD, Pallante KM and Adams SL: The splicing pattern of fibronectin mRNA changes during chondrogenesis resulting in an unusual form of the mRNA in cartilage. J Biol Chem 266: 5918-5924, 1991

32. Han F, Adams CS, Tao Z, et al: Transforming growth factor- $\beta 1$ (TGF-ß1) regulates ATDC5 chondrogenic differentiation and fibronectin isoform expression. J Cell Biochem 95: 750-762, 2005.

33. Han F, Gilbert JR, Harrison G, et al: Transforming growth factor-betal regulates fibronectin isoform expression and splicing factor SRp40 expression during ATDC5 chondrogenic maturation. Exp Cell Res 313: 1518-1532, 2007.

34. Moriguchi Y, Matsubara H, Mori Y, et al: Angiotensin IIinduced transactivation of epidermal growth factor receptor regulates fibronectin and transforming growth factor-beta synthesis via transcriptional and posttranscriptional mechanisms. Circ Res 84: 1073-1084, 1999.

35. Korfhagen TR, Swantz RJ, Wert SE, et al: Respiratory epithelial cell expression of human transforming growth factor-alpha induces lung fibrosis in transgenic mice. J Clin Invest 93: 1691-1699, 1994.

36. Hardie WD, Davidson $\mathrm{C}$, Ikegami $\mathrm{M}$, et al: EGF receptor tyrosine kinase inhibitors diminish transforming growth factoralpha-induced pulmonary fibrosis. Am J Physiol Lung Cell Mol Physiol 294: 1217-1225, 2008.

37. Perugorria MJ, Latasa MU, Nicou A, et al: The epidermal growth factor receptor ligand amphiregulin participates in the development of mouse liver fibrosis. Hepatology 48: 1251-1261, 2008.

38. Sandgren EP, Luetteke NC, Palmiter RD, Brinster RL and Lee DC: Overexpression of TGF alpha in transgenic mice: induction of epithelial hyperplasia, pancreatic metaplasia, and carcinoma of the breast. Cell 61: 1121-1135, 1990.

39. Means AL, Ray KC, Singh AB, et al: Overexpression of heparin-binding EGF-like growth factor in mouse pancreas results in fibrosis and epithelial metaplasia. Gastroenterology 124: 1020-1036, 2003.

40. Blaine SA, Ray KC, Branch KM, Robinson PS, Whitehead RH and Means AL: Epidermal growth factor regulates pancreatic fibrosis. Am J Physiol Gastrointest Liver Physiol 297: G434-G441, 2009. 